\title{
CLIMATE CHANGE IMPACT ON ECONOMY
}

\author{
Subhash J. Deshmukh and Rushikesh N. Bhagat \\ Dada Patil Rajale Arts, Science and Commerce college, Adinathnagar, \\ Tal: Pathardi ,Dist:Ahamednagar,(MH) .
}

Communicated : 12.02 .20
Revision :08.03.20 \& 10.4.2020 Accepted : 25.05.2020
Published: 30.05.2020

\section{INTRODUCTION:}

This article describes the economic impacts of climate change. Given the inherent nature of economic forecasting, which involves significant degrees of uncertainty, estimates of the results of global warming over the 21st century have varied widely. Many analyses, such as that of the Stern Review presented to the British Government, have predicted reductions by several percent of world gross domestic product due to climate related costs such as dealing with increased extreme weather events and stresses to low-lying areas due to sea level rises. However, attempting to quantify the economic costs of global warming as a percentage of GDP has its inherent problems because it omits the ecological effects of climate climate that are difficult to associate with a dollar value such as loss of human life or biodiversity, or those effects that will have economic consequences later on. To summarize, most studies by independent economists looking at the effects of climate change have suggested that climate change does negatively affect the global economy, though the issue remains intensely debated. Climate change is unequivocal The change alters all

sustainable development dimensions (i.e. economic, social, and environmental), and hence the potential development path ways for a given nation or region. It even is claimed that climate change to be the "mother" of all problems to show its irreversible impacts. The set of mechanisms in which climate change affects economic and environmental outcomes are too vast and complex to investigate comprehensively. Therefore, it is intellectually daunting to deal with it . Partially because of its bio-physical dependence on the two metrological variables, precipitation and temperature, among others, and partially due to relatively quantifiable impacts on it; the literature on economic impacts of climate change so far, however, is inclined to production and productivity on agricultural sector. Even on this line we do have very limited literature assessing the indirect impacts accruing to change in price and comparative advantage. Next to agriculture, the fast growing literature on the impacts of climate change has made attempts to assess the impacts of climate change on human health.

2. The Impacts of climate change on various sectorS:- Climate change impacts can be measured as an economic cost. This is particularly well-suited to market impacts, that is impacts that are linked to market transactions and directly affect GDP. Monetary measures of non-market impacts, e.g., impacts on human health and ecosystems, are more difficult to calculate.

A) Agriculture :- Depending on underlying assumptions, studies of the economic impacts of a doubling in atmospheric carbon dioxide $(\mathrm{CO} 2)$ from pre-industrial levels conclude that this 
would have a slightly negative to moderately positive aggregate effect (i.e., total impacts across all regions) on the agricultural sector. This aggregate effect hides substantial regional differences, with benefits mostly predicted in the developed world and strongly negative impacts for populations poorly connected to regional and global trading systems.

Agriculture are highly dependent on the climate. Increases in temperature and carbon dioxide (CO2) can increase some crop yields in some places. But to realize these benefits, nutrient levels, soil moisture, water availability, and other conditions must also be met. Changes in the frequency and severity of droughts and floods could pose challenges for farmers and ranchers and threaten food safety. Meanwhile, warmer water temperatures are likely to cause the habitat ranges of many fish and shellfish species to shift, which could disrupt ecosystems. Overall, climate change could make it more difficult to grow crops, raise animals, and catch fish in the same ways and same places as we have done in the past. The effects of climate change also need to be considered along with other evolving factors that affect agricultural production, such as changes in farming practices and technology.

B) Non-market impacts :- predicted that climate change would likely result in pronounced nonmarket impacts. Most of impacts were predicted to be negative. The literature assessment by Smith et al. (2001) suggested that climate change would cause substantial negative health impacts in developing countries. Smith et al. (2001) noted that few of the studies they reviewed had adequately accounted for adaptation. In a literature assessment, Confalonieri et al.found that in the studies that had included health impacts, those impacts contributed substantially to the total costs of climate change.
C) Market sector :- In 2019 the International Labour Organization published a report titled: "Working on a warmer planet: The impact of heat stress on labour productivity and decent work", in which it claims that even if the rise in temperature will be limited to 1.5 degree, by the year 2030, Climate Change will cause losses in productivity reaching $2.2 \%$ of all the working hours, every year. This is equivalent to 80 million full time jobs, or 2,400 billion dollars. The sector expected to be most affected is agriculture, which is projected to account for $60 \%$ of this loss. The construction sector is also projected to be severely impacted and accounts for $19 \%$ of projected losses. Other sectors that are most at risk are environmental goods and services, refuse collection, emergency, repair work, transport, tourism, sports and some forms of industrial work.

Climate change driven migration possibly helped to trigger Brexit - the exit of Britain from European Union. The uncertainty about Brexit has shrunk the British economy in 2019], and may cause it to contract further in the future Brexit can make it shrink it much more.

D) Affect Non-Agriculture Industries :- economic impacts of climate change on non-agriculture production and productivity is also immense and quantifiable so that should be given attention. Assessing and quantifying the impacts on secondary and tertiary level of economic activities, however, is too complex and tiresome. Partially, it needs understanding the inter linkage between the primary industries and secondary and tertiary level of economic sectors and the product, financial, and factor markets of these industries. Add to these, assessing the impacts on economic activities other than agriculture are complex as ways through which climate change affects these economic activities are many and can't easily be modelled. Herein below, we have depicted the conceptual framework in which the climate 
change may affect the nonprimary industries (i.e. manufacturing and service Industries) .

1. Impacts through Labour Productivity :climate change through its effects on mean temperature and precipitation, frequency of extreme weather events, droughts, flooding, and wind storms, will pose a real challenge to labour productivity and hence any sector which uses labour. Presuming that labour is being paid based on its productivity in the primary sectors, as in a standard macro and labour economic analysis, the manufacturing and service sector will be affected not only due to mortality and morbidity to labourers engaged within the sector only but also due to fall in productivity of labourers in the primary sector. Put another way, by presuming labour will be paid based on its marginal productivity, as in any standard economic analysis, demand for manufactured goods and services will fall due to fall in farm/agricultural income.

2. Indirect Impacts through Markets :- It is plain fact the any industry needs financial loan and insurance for its business. The manufacturing industry, too, needs insurance for the risks and uncertainty associated with the industry. The more risky and uncertain the industry you are engaged with the higher is risk premium needed to be paid. Therefore, those industries which are highly affected by weather changes (e.g. construction and housing industry); produce perishable goods and services (e.g. hotels, restaurants, food and brewery); tourist destinations (e.g. beach) will be subjected to high risk premium which in turn affects the production cost for the industries. It will also be very difficult for industries (whose business is sought as risky and uncertain) getting financial loans. We can also look at the labour market. Increased risks and uncertainties associated with working environment does mean increased occupational health risks which in turn provokes workers to seek better wages and salaries to reduce gross profit of manufacturing industry. On the other hand, non-agriculture industries particularly those using unskilled labour may benefit from cheap labour due to increased rural-urban migration which is pushed by fall in agricultural production and productivity due to climate change.

E) Impact on a particular industry:-

1. Construction and Housing Industry :- Climate change alters the magnitude, intensity and frequency of climate variables. The magnitude, pattern, intensity and loads of mean annual temperature, precipitation, wind (moisture, movements, direction) will be different with change in the earth climate. These events, in turn, affect those industries whose operation is highly associated with the climate variables. Construction and housing industry is among them. The construction and housing industry consists of general (such as residential and commercial buildings), heavy or civil engineering (such as bridges, high ways), and industrial (which involves building and/or assembling infrastructure, such as electric power works) constructions. Significant variations in variables of climate (temperature, precipitation, and wind) have tangible effect on the process and engineering of construction. A rainy winter, hot summer, and windy spring affect the construction process. Such events, for instance, delay the contractual period which in turn breeds additional costs to the contactor. The delays in turn affect the reputability and goodwill of the real estate firms. On the other hand, coastal erosion, subsidence, flooding, and change in draining systems influence the choice of construction site to which effect geological survey costs increase. Add to these, increase in temperature and extreme weather events increase the depreciation rate (wear and tear of buildings) of existing structures.

2. On Food and Brewery Industries :- Unlike the case of construction and housing industries 
where the impacts primarily owe to the change in climate variables and increased possibility of extreme weather events; the impacts on food and brewery industries primarily owe to repercussion effects of climate change through agricultural production and productivity. Note that by food and brewery we do mean industries which depend on crop and/or livestock production. Livestock production is affected due to both the quality and amount of forage from grasslands and direct effects on livestock due to higher temperature. Hence, not only the food industry that depends on it (e.g. milk production) but also those which depend on skin and hide (e.g. leather textile industry) are highly affected. The impact on the food and brewery industry still is not even. It depends on the climate sensitivity of the raw materials they are using.

3. Timber, Fishery and Mining and Quarrying :Timbering, fishing, and mining are other major economic sectors whose production and productivity highly hinges on the health of the ecosystem. These economic sectors are also primary economic activities by level of production even though are different in their nature of production. Therefore, a comprehensive review on the economic impacts on these industries should incorporate from the direct bio-physical relationship between climate change to the final supply of goods and services which directly or indirectly take the resources produced by these sectors as raw materials for further processing. For example, any impact on fishing will be transmitted to the fish food industries as we discussed in the earlier subsection. Impacts on timber production can also be taken as a proxy for impacts on furniture and pulp industries. Such comprehensive studies, assessing the impacts from the biophysical relationship to the supply and price of final goods and services, however, were hardly available. The discussions herein below, therefore, are based on the impacts based on bio-physical dependence of the sectors with the climate and climate change.

4. Other sectors:- A number of other sectors will be affected by climate change, including the livestock, forestry industries. Other sectors sensitive to climate change include the energy, insurance, tourism and recreation industries. The aggregate impact of climate change on most of these sectors is highly uncertain

F) Conclusion :- Climate change is a leading agendum today. Its impacts, vulnerability and adaptation issues have drawn many scholars from the political, academic, and research sphere. The economic literature on the impacts of climate change, however, is inclined to the impacts on agricultural production and productivity. There is also thin but growing literature on the impacts of climate change on human health. This, however, make the economic impacts due to climate change incomplete as non-agriculture industries (manufacturing and services industries) are also being affected. Moreover, impacts on these sectors are high in absolute terms as the two industries contribute to more to national GDP in absolute terms than agriculture in many countries.

therefore, future research on the topic should identify the transmission mechanisms-from regions to regions, from sector to sector, from sector to economy wide; should focus on the long run too; and should identify the interplay and relative contribution of different climate factors (temperature, precipitation, wind storms). Put another way, studies on the economic impacts of climate change should be stretched out to gauge some more economic activities; possible long term effect; and some more channels through which climate change impose challenges to human beings. It is through this that the impacts can be estimated better; reports echoing only poor nations will be 
affected can get lesser and lesser; and can enhance political commitment on mitigation and adaptation activities.

\section{REFERENCES:}

New Chandra S.P. (2009) "Agriculture and Rural development in India Science 1947" New publication, New Delhi.

Intergovernmental Panel on Climate Change (IPCC), "Summary for Policymakers. Climate Change 2007: The Physical Science Basis," In: Contribution of Working Group I to the Fourth Assessment Report of the Intergovernmental Panel on Climate Change, Cambridge University Press, Cambridge, 2007.

A. Iglesias, "Climate Change and Agriculture," CGE Hands on Training Workshop on V\&A Assessment of the Asia and the
Pacific Region, Jakarta, 20-24 March 2006.

Gare V. k. and Dhingra C, 2002, Micro Economics and Indian Economic Environment, sultan chand sons, New Delhi.

Manisha Dubey " problems of agriculture growth in India " Published by G.S. Rawat for Cyber Tech Publications, New Delhi.

J. M. Griffin, "Introduction: The Many Dimensions of the Climate Change Issue," In: J. M. Griffin, Ed., Global Climate Change: The Science, Economics, and Politics, Edward Elgar Publishing, Cheltenham, pp. 1-24.

Agricultural Development and Economic Transformation Subrata Ghatak and Ken Ingersent ,1984, Agriculture and Economic Development, New Delhi. 